\title{
Penggunaan Motor BLDC pada Mesin CNC dengan Teknologi InstaSPIN- MOTION dari Texas Instrument
}

\author{
Jimmy Linggarjati \\ Rudy Susanto \\ jimmyl@binus.edu
}

\begin{abstract}
Abstrak
Dari Hibah Dikti, didapatkan pendanaan untuk melakukan eksperimen dengan motor BLDC dan belajar tentang bagaimana motor tersebut bekerja. Hasil utama dari penelitian ini adalah sebuah pembuktian bahwa teknologi InstaSPIN-Motion dari Texas Instruments, dapat diterapkan pada mesin CNC yang telah kita buat dengan dana dari Hibah Dikti. Tulisan ini juga mengulas tulisan-tulisan ilmiah sebelumnya tentang topologi dan algoritma kontrol dari motor BLDC. Hasil dari percobaan yang dilakukan dengan menggunakan kit evaluasi (yaitu: "The Low Voltage High Current Evaluation Kit" [4]) dari Texas Instrument, juga dilaporkan dalam tulisan ini.
\end{abstract}

Kata kunci: Motor BLDC (Brushless DC), InstaSPIN ${ }^{T M}$, InstaMotion $^{T M}$, Mesin CNC (Computer Numerical Control).

\section{Pengenalan Motor BLDC}

Motor BLDC semakin banyak digunakan pada produk-produk disekitar kita, baik secara komersial maupun dalam dunia industri. Salah satu kelebihan dari motor BLDC dibandingkan dengan motor DC adalah efesiensi yang lebih baik dikarenakan ia tidak menggunakan brush (brushless). Dan, diikuti dengan kemajuan prosesor ARM (> $60 \mathrm{MHz}$ ), maka sistem kontrol elektronik motor BLDC menjadi lebih murah saat ini. Dengan dana kurang lebih 500 dolar Amerika, kita dapat membeli sebuah kit evaluasi motor dari Texas Instruments, seperti dapat dilihat pada gambar 1.

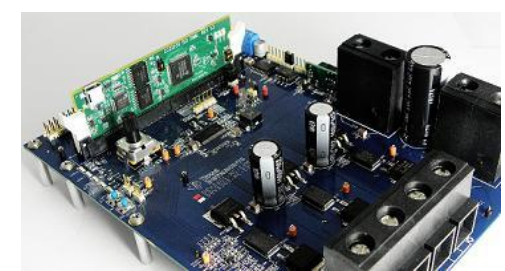

Gambar 1: Low Voltage High Current Evaluation Kit Texas Instrument

\subsection{Ulasan Prinsip Kerja Motor [1]}

Terdapat empat konsep dasar yang melandasi bagaimana sebuah motor listrik bekerja, yaitu:

\section{Gaya Magnetik}

Secara mendasar, gaya magnetik didapat dari suatu batang magnetik atau dari sebuah konduktor yang dialiri arus. Kutub magnet memiliki garis magnetik yang bergerak dari kutub Utara ke kutub Selatan, seperti terlihat dari gambar $2^{1}$.

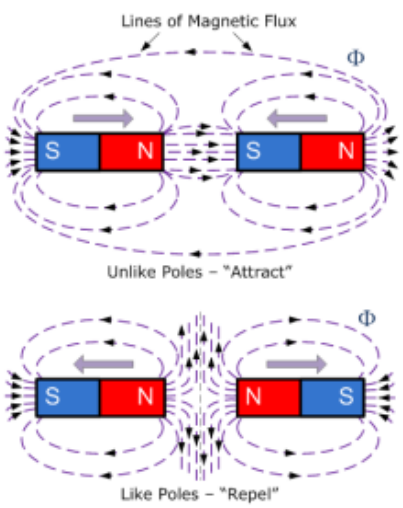

Gambar 2: Gaya Magnetik

2. Aturan Tangan Kiri (Left Hand Rule)

Aturan Tangan Kiri digunakan untuk menentukan arah dari Gaya yang terjadi dalam sebuah konduktor yang berada didalam pengaruh medan magnet dari Utara ke Selatan. Gambar $3^{2}$ mengilustrasikan gaya elektro-magnetik, akibat dari Aturan Tangan Kiri ini. Besarnya gaya ini $(F)$ dapat dihitung dengan menggunakan persamaan berikut:

$$
F=B I L \sin (\theta)
$$

Dimana $\mathrm{F}$ adalah gaya elekro-magnetik, B adalah kerapatan medan magnetik, I adalah arus pada konduktor, $\mathrm{L}$ adalah panjang dari konduktor yang terpengaruh oleh kerapatan medan magnetik (B), $\theta$ adalah sudut antara $\mathrm{B}$ dan $\mathrm{L}$, seperti diilustrasikan pada gambar $4^{3}$.

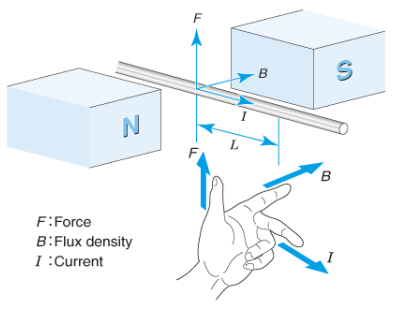

Gambar 3: Left Hand Rule

${ }_{1}^{1}$ Taken from http://www.electronics-tutorials.ws/electromagnetism/magnetism.htm ${ }^{2}$ Taken from http://www.nidec.com/en-NA/technology/motor/basic/00012/? prt=1 ${ }_{3}$ Taken from http://173.255.218.22/library/physics/motors-generators/the-motoreffect/lesson-2-theory-the-motor-effect 


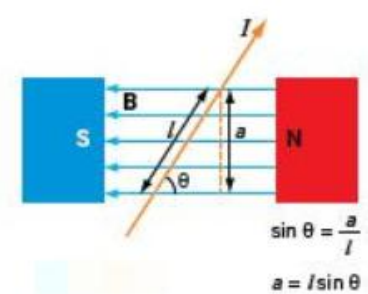

Gambar 4: B and L Relation

\section{Aturan Tangan Kanan (Right Hand Rule)}

Dikarenakan Aturan-Tangan-Kiri, dalam sebuah rancangan motor, maka terjadi sebuah pergerakan sudut dari konduktor yang berada dalam medan magnetik tersebut. Hal ini menimbulkan gaya elektro-motive lainnya, yang disebut dengan BEMF (Back Electro Motive Force). Besarnya gaya elektro-motive yang terserap oleh konduktor dikarenakan oleh medan magnetik, dapat dihitung dengan menggunakan persamaan berikut:

$$
E=B L v \sin (\theta)
$$

Dimana $E$ adalah gaya elektro-magnetik hasil induksi dengan satuan volt [V], v adalah keceapat gerak dari konduktor tersebut dalam satuan meter per detik [m/s], $\theta$ sama seperti sebelumnya, adalah perbedaan sudut antara $B$ dan $L$ dalam satuan radian [rad]. Polaritas E terhadap B dan V, di-ilustrasikan dalam gambar $5^{4}$.

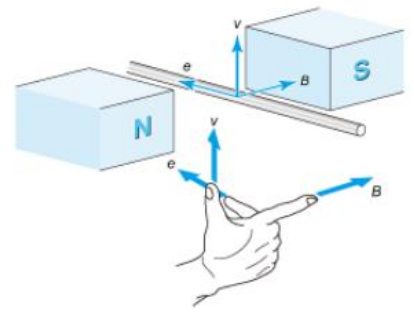

Gambar 5: Right Hand Rule

\section{Aturan Sekrup Tangan Kanan}

Jika sebuah arus DC mengalir melalui sebuah konduktor lurus, maka sebuah medan magnetik akan tercipta secara induksi, dimana arah dari medan magnetik tersebut mengikuti Aturan Sekrup Tangan Kanan, seperti terlihat pada gambar $6^{5}$. Namun dalam sebuah aplikasi solenoid, konduktor tersebut dibentuk menyerupai koil. Oleh karena itu, arusnya membentuk koil. Kutub magnetik yang dihasilkan dari arus koil dapat ditentukan juga dengan menggunakan Aturan Sekrup Tangan Kanan, seperti terlihat pada

${ }^{4}$ Taken from http://www.nidec.com/en-NA/technology/motor/basic/00013/ ${ }^{5}$ Taken from https://www.patana.ac.th/secondary/science/anrophysics/ntopic6/ commentary.htm gambar $7^{6}$. Keuntungan arus-koil adalah Kerapatan Medan Magnet (B) yang lebih besar, dimana arah kutub Utara - Selatan dapat ditentukan dengan Aturan Sekrup Tangan Kanan ini.

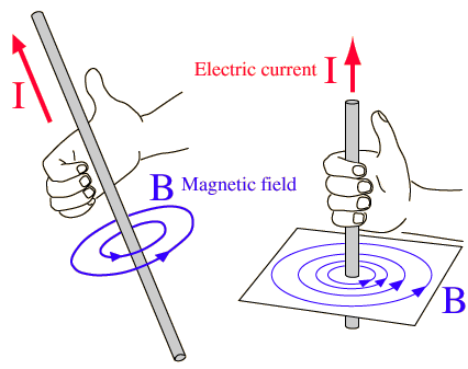

Gambar 6: Aturan Sekrup Tangan Kanan (Right Hand Cork Screw Rule)

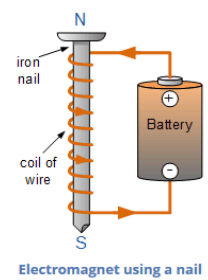

Gambar 7: Konduktor dalam Loop

\subsection{Kemajuan Teknologi Penggerak Elektronik}

Tulisan [2] merangkum kemajuan teknologi penggerak elektronik yang digunakan pada motor BLDC. Dari tulisan tersebut, terdapat beberapa istilah yang digunakan khusus pada motor BLDC. Dari pencarian-web terhadap terminologi yang digunakan dalam [2], kita menemukan tulisan lainnya yang terkait dengan penelitian di bidang motor BLDC. Topologi sistem kontrol dalam BLDC terbagi dua yaitu VSI (Voltage Source Inverter) and CSI (Current Source Inverter). Sementara konstruksi rotor motor BLDC juga terbagi dua kategori utama, yaitu rotor tipe Pemasangan-padapermukaan (Surface-mounted magnet) dan roto tipe magnet terbenam (Embedded magnet) [3].

Dari sudut pandang eksperimen, kita memilih perangkat-pengembangan (development kit) dari Texas Instrument (TI) [4]. Alasan utama dalam memilih produk tersebut adalah karena perangkat tersebut memiliki dokumentasi yang baik dari TI, sehingga kita tidak perlu membuat program dari awal, dan dapat berkonsentrasi pada cara kerja dasar dari motor BLDC tersebut.

Dalam teknik kontrol dari motor BLDC, terdapat banyak ide-ide cemerlang terkait algoritma dan sistem kontrol elektronik dari motor BLDC. Salah

${ }^{6}$ Taken from http://www.electronics-

tutorials.ws/electromagnetism/electromagnets.htm 
satu ide yang paling banyak di diskusikan adalah upaya untuk menghilangkan sensor enkoder pada motor BLDC, melalui teknik sensorless [5][6][7]. Teknik sensorless dapat meningkatkan reliabilitas dari sistem motor BLDC ini. Namun, berdasarkan bacaan dan percobaan pada [8], kita simpulkan dua hal penting terkait teknik sensorless:

1. Untuk aplikasi yang membutuhkan sistem kontrol posisi yang akurat, seperti dalam aplikasi mesin CNC, maka teknik sensorless tidak dapat digunakan. Alasan utama adalah Back Electro Motive Force (BEMF) terlalu kecil untuk dideteksi, terutama pada aplikasi dengan kecepatan rendah.

2. Posisi rotor awal, yaitu posisi diam pada rotor, masalah yang sama timbul, yaitu BEMF terlalu kecil untuk dideteksi pada pergerakan dengan kecepatan rendah, yang terjadi sering dalam aplikasi mesin CNC.

Kemudian, dari sudut pandang pemodelan motor, dapat disimpulkan bahwa terdapat dua teknik identifikasi parameter untuk PID (Proportional Integral Derivative), yaitu dengan menggunakan eksperimen [9][21], dan dengan menggunakan pemodelan matematis [10]-[13].

Sementara dari [14]-[17], kita belajar bahwa terdapat kecenderuangan untuk melakukan prototipe kontrol secara singkat (rapid control prototyping), disebabkan oleh persaingan bisnis dalam produksi barang-barang konsumen, yang menggunakan motor BLDC sebagai salah satu komponen pemrosesan barang-barang tersebut.

Dalam tulisan [18], sebuah penelitian perbandingan dilakukan antara algoritma motor BLDC industri dengan algoritma motor BLDC Texas Instrument. Dan berdasarkan informasi tersebut, kita membuat keputusan untuk menggunakan program yang sudah dibuat oleh TI, dibandingkan dengan memahami dan membuat algortima program dari awal. Alasan pertama dari keputusan ini adalah, kita memiliki pengetahuan dasar (knowhow) yang minim terkait topologi sistem kontrol dari motor BLDC ${ }^{7}$. Alasan kedua adalah kit evaluasi elektronik yang ditawarkan oleh Texas Instrument, jauh lebih murah dibandingkan dengan produk motor driver dari industri. Meskipun disebutkan dalam [18], bahwa dalam produk motor BLDC industri, ia memiliki kemudahan dari sisi penggunaan parameter kontrol-nya di lapangan, dibandingkan dengan kit evaluasi dari TI. Namun, kita telah memahami melalui eksperimen, bahwa algoritma software InstaSPIN $^{T M}$ dan InstaMOTION ${ }^{T M}$ dari TI, telah terbukti bermanfaat dalam proses penalaan (tuning) pada sistem kontrol posisi pada sebuah motor BLDC.

Terdapat tiga tipe kontrol komutasi yang dapat diterapkan pada motor BLDC, diurutkan berdasarkan kerumitan dari algoritma komutasinya:

1. Penggunaan Hall-Sensor atau EncoderSensor

2. Zero Thresholds

3. Field Oriented Control

Dari teknik komutasi diatas, kita gunakan sensor enkoder sebagai umpan-balik posisi untuk sistem kontrol digital. Gambar 8 memperlihatkan diagram blok keseluruhan yang digunakan dalam percobaan kami.

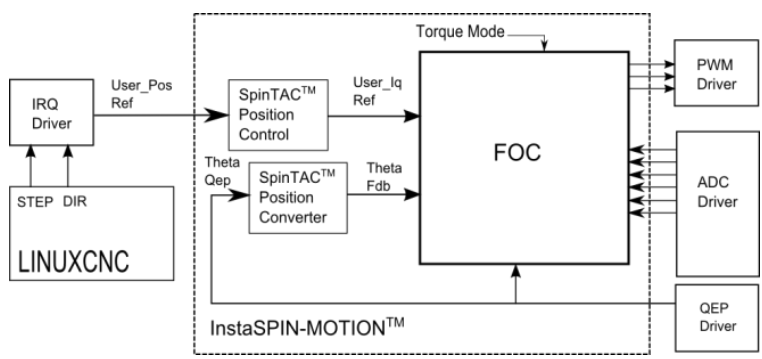

Gambar 8: Koneksi Diagram Blok dari Motor BLDC dengan Piranti Lunak LinuxCNC [19]

\section{Metodologi Experimen pada Motor BLDC dengan Sensor Enkoder}

Gambar 9 memperlihatkan kit evaluasi dan motor BLDC yang digunakan dalam experimen ini. Texas Instruments mengeluarkan sebuah dokumentasi berjudul "instaspin-labs.pdf", yang berisi rincian experimen penggunaan kit evalusi tersebut. Untuk experimen ini, kita menggunakan "Low Voltage, High Current Motor Drive EVM (DRV8301)".

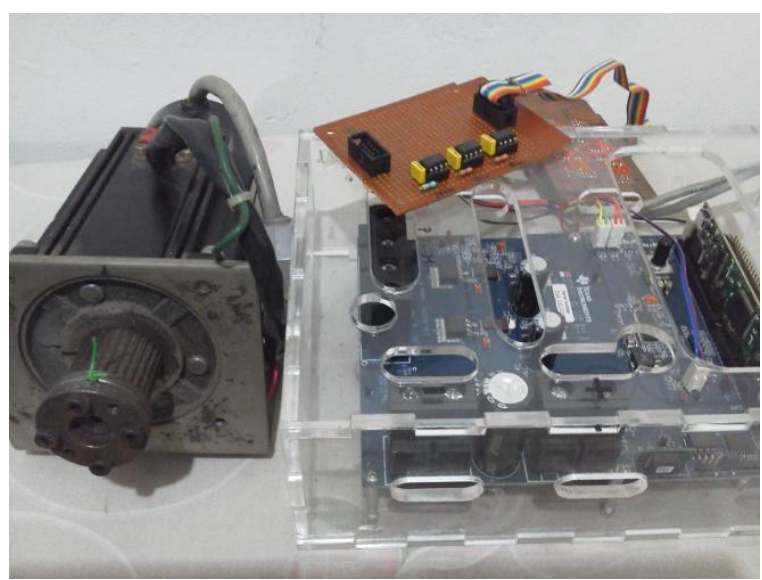

Gambar 9: Foto dari Motor BLDC dan Kit Evaluasi Kontrol 
Berikut ini adalah urutan eksperimen yang dilakukan:

1. Lab 2a - Penggunaan InstaSPIN

Pada eksperimen pertama ini, kita mendapatkan dua parameter penting dari sebuah motor tertentu, yaitu motor Tamagawa 400Wat. (seperti terlihat pada gambar 9):

(a) Resistansi (2.209746 Ohm)

(b) Induktansi (0.006565256 Henry)

2. Lab 5c - Identifikasi Inersia menggunakan InstaSPIN-MOTION (Inertia Identification) Dari experimen ini, kita mendapatkan inersia dari sistem motor Tamagawa 400W, dengan menggunakan piranti lunak instaSPIN-MOTION. Hasil dari eksperimen ini adalah dua nilai penting, terkait inersia dan gaya-gesek pada motor BLDC ini:

(a) Inersia: 0.1514648795

(b) Gesekan: 0.4883004427

Kedua nilai ini diambil saat motor BLDC terhubung secara mekanik pada salah satu axis dari mesin CNC.

3. Lab 5 e - Penalaan Sistem Kontrol Kecepatan dengan InstaSPIN-MOTION Pada eksperimen ini, sistem lebar-pita diatur pada angka 40 rad/s. Lebar-pita dari sistem adalah sebuah pengukuran tentang seberapa cepat sistem ini menanggapi gangguan lain, sebagai contoh dari kondisi tanpa-beban ke sebuah kondisi denganbeban, atau sebaliknya. Namun lebar-pita yang terlalu tinggi, dapat menyebabkan dapat menyulitkan sistem untuk berubah ke posisi tertentu, dan ini dapat menyebabkan osilasi pada sistem tersebut.

4. Lab 12a - Identifikasi Inersia dengan

Sensor Enkoder

Seperti pada Lab 5c, dalam eksperimen ini, kita mengukur inersia dari sistem. Perbedaannya adalah sebuah enkoder digunakan sebagai umpan-balik posisi rotor dari motor BLDC. Dengan menggunakan enkoder, estimator posisi tidak lagi diperlukan. Experimen ini menghasilkan data sebagai berikut:

(a) Inersia: 0.1315711141

(b) Gesekan: 0.1667294502

5. Lab 12b - Penggunaan InstaSPIN-MOTION dengan Sistem Sensor Enkoder

Pada experimen ini, kita menggunakan sebuah sistem kontrol kecepatan pada motor BLDC dengan teknologi InstaSPINMOTION. Dari hasil pengamatan, maka dapat disimpulkan bahwa dengan penggunaan enkoder sebagai sensor posisi, motor BLDC dapat digerakkan dari posisi diam, dan ia memiliki respons yang lebih baik pada kecepatan rendah, dibandingkan dengan penggunaan FAST Estimator [4].

6. Lab 13a - Penalaan InstaSPIN-MOTION sebagai Kontrol Posisi

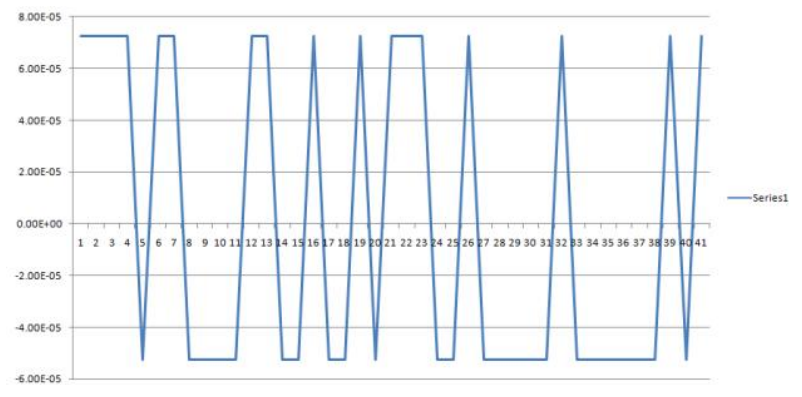

Gambar 10: Selisih Kesalahan Posisi Terukur dari Sistem Kontrol Posisi

Experimen ini adalah percobaan terakhir yang perlu kita coba, sebelum kita menambahkan dan mengubah kode program, agar dapat bekerja dengan mesin CNC. Pada lab 13a ini, kita menggunakan library tambahan bernama SpinTAC Position Control, untuk memerintahkan motor BLDC agar bergerak ke suatu posisi tertentu. Library SpinTAC, memiliki dua fungsi utama yang akan digunakan, yaitu: STPOSCTL_setPositionReference_mrev() dan STPOSCONV_run(). Dari hasil experimen ini, kita dapat simpulkan bahwa sistem kontrol posisi dengan InstaSPINMOTION, telah bekerja dengan baik pada motor Tamagawa 400W, dengan menggunakan sebuah lebar-pita $40 \mathrm{rad} / \mathrm{s}$. Gambar 10 menunjukan data kesalahan posisi yang diambil dari piranti lunak InstaMotion dari Texas Instrument ${ }^{8}$. Jangkauan dari kesalahan posisi berada dalam batasan +/- $7 * 10^{-5} \mathrm{~mm}$, dimana angka tersebut berada dalam toleransi mekanik dari mesin CNC [19], untuk dapat dianggap sebagai posisi diam.

Dari Hibah Dikti (hibah pemerintah), kita telah menghasilkan sebuah mesin CNC (lihat gambar 11) yang menggunakan piranti lunak LinuxCNC. Sinyal kontrol yang dikeluarkan oleh Linux CNC berupa sinyal step dan dir(ection). Oleh karena itu, agar dapat menerima sinyal step dan dir, kita gunakan dua interrupt pada input pin INTR1 dan INTR2. Lalu sinyal step, dihitung dan dikirim ke fungsi STPOSCTL_setPositionRef-erence_mrev(),

8Those data are taken using CCS software from TI http://www.ti.com/tool/CCSTUDIO 
sehingga motor BLDC dapat bergerak ke posisi yang di-instruksikan tersebut.

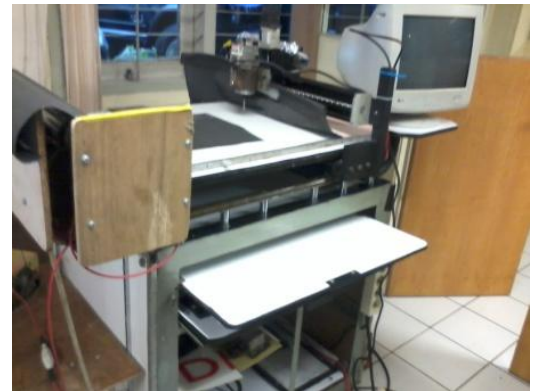

Gambar 11: Mesin CNC 3 Axis - LinuxCNC

Dari gambar yang dihasilkan oleh mesin CNC dengan menggunakan penggerak motor BLDC (lihat gambar 12), maka dapat dilihat bahwa kit evaluasi dari Texas Instrument [4], mampu mengikuti pergerakan posisi yang diinginkan oleh LinuxCNC, dengan keakuratan yang sama dengan ukuran gambar pada komputer. Oleh karena itu, tujuan utama dari penggunaan motor BLDC dalam mesin CNC telah tercapai dengan baik.

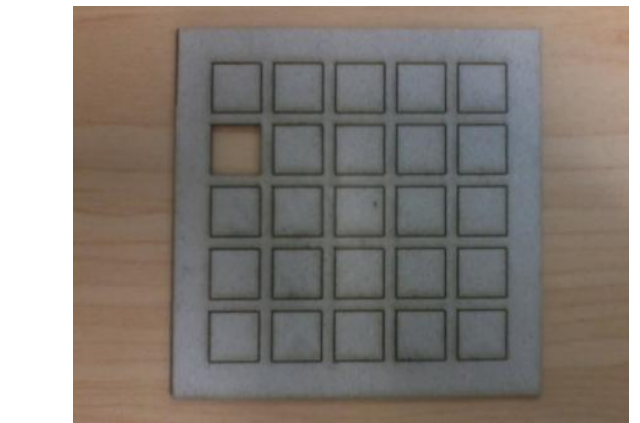

Gambar 12: Pola Gambar Kotak dengan Penggerak Motor BLDC

\section{Kesimpulan}

Dengan Hibah Dikti 2015, kita telah mampu menggunakan motor BLDC sebagai penggerak axis dalam mesin CNC. Meskipun penelitian ini tidak menghasilkan algoritma sistem kontrol motor BLDC baru, namun kita bangga menjadi peneliti pertama dalam area motor BLDC di dalam universitas Bina Nusantara.

Praktikum untuk melakukan experimen pada motor Synchronous ${ }^{9}$ diperlukan dalam dunia pendidikan dan industri secara umum. Tanpa praktikum tersebut, sebuah penelitian mendalam terkait motor BLDC akan menjadi sulit. Dan akitbatnya, industri yang tidak mendukung pendidikan dalam teknologi motor synchronous, tidak akan dapat bertahan dalam persaingan dunia.

9E.g. Laboratorium at Universitas Virginia TECH http://www.ece.vt.edu/ece3354/

\section{Ucapan Terima Kasih}

Penelitian experimental ini, pada motor Servo BLDC, tidak akan dimungkinkan tanpa bantuan hibah dari Hibah Bersaing Dikti 2015 dan dukungan laboratorium jurusan Sistem Komputer Universitas Bina Nusantara.

\section{Daftar Pustaka}

1. Jian Zhao/Yangwei Yu, Brushless DC Motor Fundametals Application Note, AN047, July 2011.

2. State of the Art on Permanent Magnet Brushless DC Motor Drives - Journal of Power Electronics, Vol. 9, No. 1, January 2009.

3. Sakae Yamamura, Saliency torque and Vcurve of permanent-magnet-excited synchronous motor - June 132000 - Proc. Japan Acad, 76, Ser. B (2000).

4. Three Phase BLDC \& PMSM Motor Kit with DRV8301 and InstaSPIN-enabled Piccolo TMS320F28069M MCU, http://www.ti.com/tool/drv8301-69m-kit (accessed on 7th November 2014).

5. What is FOC and what good is it, http://www.maccon.de/fileadmin/ftproot/ Field-Oriented-Control.pdf (accessed on 7th November 2014).

6. Bilal Akin and Manish Bhradwaj, Sensorless Trapezoidal Control of BLDC Motors, Texas Instruments.

7. Bilal Akin and Manish Bhradwaj, Sensorless Field Oriented Control of 3-Phase Permanent Magnet Synchronous Motors, Texas Instruments.

8. InstaSPIN Projects and Labs User Guides MotorWareTM Software, http://www.ti.com/tool/motorware.

9. Finn Haugen, Ziegler-Nichols ${ }^{\mathrm{TM}}$ Closed-Loop Method, http://techteach.no

10.Yun Li ; Glasgow Univ., UK ; Kiam Heong Ang ; Chong, G.C.Y., Patents, software and hardware for PID control: an overview and analysis.

11.Yun Li ; Glasgow Univ., UK ; Kiam Heong Ang ; Chong, G.C.Y., PID Control System analysis and design.

12.Sigurd Skogestad, Probably the best simple PID tuning rules in the world.

13. A. Purna Chandra Rao, Y. P. Obulesh, Ch. Sai Babu - Mathematical Modeling Of BLDC Motor With Closed Loop Speed Control Using PID Controller Under Various Loading Conditions - ARPN Journal of Engineering 
and Applied Sciences Vol. 7, No. 10, October 2012 ISSN 1819-6608.

14. Chaoji Chen, Na Zhao, Hongtao Jin, Yongjin Zhao - Design and Implementation of the Servo Control System Based on DSP Computer and Information Science - Vol. 3, No. 4; November 2010.

15. Radu Duma, Mirela T., Petru Dobra - BLDC motor control using rapid control prototyping, CEAI, Vol.12, No.1, pp. 55-61, 2010.

16. Longya Xu, Minghua Fu, Li Zhen - A DSP Based Servo System Using Permanent Magnet Synchronous Motors (PMSM) - The Ohio State University Department of Electrical Engineering 2015 Neil Avenue Columbus, $\mathrm{OH} 43210$.

17. Radu Duma, Petru Dobra, Mirela Trusca, Dorin Petreus, Daniel Moga - Towards a Rapid Control Prototyping Toolbox for the Stellaris LM3S8000 Microcontrollers; Preprints of the 18th IFAC World Congress
Milano (Italy) August 28 - September 2, 2011.

18. Matthias Blank, Philipp Lhdefink, Benjamin Reinhardt, Armin Dietz - Evaluation Of A New Microcontroller Based Solution For Sensorless Control Of Electrical Drives, Proceedings of the 6th European Embedded Design in Education and Research, 2014.

19.Jimmy Linggarjati; Rinda Hedwig, Manually Interchangeable Heads of Homemade Computer Numerical Control (CNC) Machine - Internetworking Indonesia Journal Vol.4/No.1 B (2012).

20. P.M. Meshram, Rohit G. Kanojiya - Tuning of PID Controller using Ziegler-Nichols Method for Speed Control of DC Motor IEEE- International Conference On Advances In Engineering,Science And Management (ICAESM -2012) March 30, 31,2012 . 